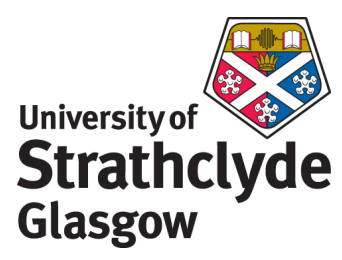

Gibson, L.T. (2010) Acetic and formic acids emitted from wood samples and their effect on selected materials in museum environments. Corrosion Science, 52 (1). pp. 172-178. ISSN 0010-938X

http://strathprints.strath.ac.uk/27572/

This is an author produced version of a paper published in Corrosion Science, 52 (1). pp. 172-178. ISSN 0010-938X. This version has been peer-reviewed but does not include the final publisher proof corrections, published layout or pagination.

Strathprints is designed to allow users to access the research output of the University of Strathclyde. Copyright $(C$ and Moral Rights for the papers on this site are retained by the individual authors and/or other copyright owners. You may not engage in further distribution of the material for any profitmaking activities or any commercial gain. You may freely distribute both the url (http://strathprints.strath.ac.uk) and the content of this paper for research or study, educational, or not-for-profit purposes without prior permission or charge. You may freely distribute the url (http://strathprints.strath.ac.uk) of the Strathprints website.

Any correspondence concerning this service should be sent to The Strathprints Administrator: eprints@cis.strath.ac.uk 


\title{
Acetic and formic acids emitted from wood samples and their effect on selected materials in museum environments.
}

\author{
L. T. Gibson and C. M. Watt \\ Dept. of Pure and Applied Chemistry, WestCHEM, \\ University of Strathclyde, 295 Cathedral Street, Glasgow G1 1XL
}

\begin{abstract}
The concentrations of acetic acid and formic acid vapours emitted by a number of wood samples held in sealed environments were measured to assess differences between hardwood and softwood species. Three cases studies are reported where sodium formate, lead formate and acetate-based efflorescences were identified on glass, lead and calcareous artefacts held in heritage environments with elevated acetic acid and formic acid vapours. Simulated experiments were undertaken to assess the affect of formic acid vapour on limestone, egg shell, copper, lead and brass coupons and it was confirmed that porous limestone preferentially scavenged formic acid vapours from air.
\end{abstract}

Keywords: Atmospheric corrosion, museum environment.

\subsection{Introduction}

Acetate- and formate-based corrosion, or efflorescence, products are often found on susceptible items held in museum enclosures contaminated with acetic or formic acid vapours. The source of the pollutants is attributed to the building materials used to create museum enclosures (cases, cabinets, drawers, shelving etc.). In particular acetic acid is known to emit from all natural woods with hardwoods, e.g. oak, being thought to emit the highest concentrations of acetic acid [1-4], with as much as $7 \%$ of the original weight of wood being released as acetic acid vapour over a period of 2 years at $48{ }^{\circ} \mathrm{C}$ [5]. The source of acetic acid is, in part, due to the hydrolysis of acetyl group esters in the hemicellulose, which constitutes roughly one-third of the total carbohydrate in the wood. Normally the hemicellulose components in hardwoods contain approximately $4-6 \%$ (by weight of the wood) whereas softwoods contain approximately $1-2 \% \mathrm{w} / \mathrm{w}[6]$. Softwoods are therefore generally thought to emit less acetic acid due to the lower concentration of acetyl esters, however the rate of hydrolysis is also due to the availability of water and the temperature of the environment surrounding the wood. The production of formic acid from wood is generally much lower than that of acetic acid. Its source is less well understood with one theory linking formic acid generation with the splitting of pyruvic acid during the metabolic processes of the wood [7]. Oak is now generally avoided as a material for museum furniture, however other woods such as mahogany, have been reported to be innocuous and are still recommended for museum use $[8,9]$. 
Use of well-sealed wooden storage and display units in museums and heritage institutions has led to artefact attack when acetic acid and/or formic acid vapour concentrations increase. Shell collections have been affected by the production of calcium acetate hydrate, calcium acetate hemihydrate or calcium acetate formate hydrate salts [10]. Numerous ceramics, fossils, pottery and limestone objects have been damaged by the production of calclacite, $\mathrm{Ca}\left(\mathrm{CH}_{3} \mathrm{COO}\right) \mathrm{Cl} 5 \mathrm{H}_{2} \mathrm{O}$ [11-15] or thecotrichite $\mathrm{Ca}_{3}\left(\mathrm{CH}_{3} \mathrm{COO}\right)$ ${ }_{3} \mathrm{Cl}\left(\mathrm{NO}_{3}\right)_{2} 7 \mathrm{H}_{2} \mathrm{O}$ [15-17]. Glass objects are also susceptible to corrosion with sodium formate identified as the primary corrosion product $[18,19]$. Metals items are also susceptible to organic acid attack with lead being one of the most cited cases. Lead formate [12,20] and basic lead carbonate [21-24] are two main degradation products formed on lead artifacts, although other products have also been identified $[25,26]$. In one study, lead greater than $98.8 \%$ purity was found to be heavily corroded by acid vapours whereas other leaded objects with a tin content $>1.2 \%$ were rendered resistant to corrosion [27]. Bronze [28,29], iron [30] and copper [31] have all received less attention although they still appear to be susceptible to attack.

The mechanisms of formation of efflorescent salts are complex and depend on the nature of soluble salts within the pores, or surfaces, of the objects. The salts can arise from a variety of sources including the burial environment of the object, previous cleaning or conservation treatments or the material of the object itself. However, in this particular situation, common to all is the presence of acetate or formate ions as a result of acid vapour deposition onto the object. Whatever the combinations of salts present crystallisation will occur if a supersaturated solution of the salt exits and the relative humidity of the surrounding environment supports solid phase formation. For example, examination of thecotrichite's phase diagram [32] explains why it is such an incongruent product - addition of a relatively small amount of acetate to a solution saturated with calcium, nitrate and chloride ions will lead very quickly to the stability field of thecotrichite. With a deliquescent point somewhere in the region of $80-90 \% \mathrm{RH}$, precipitation of thecotrichite will always occur in museum display or storage environments held at $50-60$ $\%$ RH.

Moisture induced deterioration of glass has been widely studied; water can condense at the surface of glass and react with alkali ions (sodium and potassium) that migrate from the internal glass network to the surface. An alkaline solution will form at the surface of the glass aiding dissolution of the silicate matrix, forming a gel-layer at the surface of the glass. When this process occurs in a polluted environment, the gel can react with pollutant gases in the air [33]. In the presence of organic acid vapours, sodium formate anhydrate is the predominant efflorescence product found on glass, even when the objects are stored in environments heavily contaminated with acetic acid vapour [33]. In such a situation, sodium acetate will undoubtedly be present in solution in the pores of the glass, however it will not precipitate as this salt possesses a deliquescent point lower than the RH of most storage or display environments (typically $50-60 \% \mathrm{RH}$ ).

In a bid to further confirm the emission of acetic and formic acid vapours from wood, the concentrations of vapours emitted from a number of fresh wooden samples were determined, so that informed choices on the potential use of wood for museum furniture can be made. This paper also reports 
the results of three small case studies where efflorescence had formed on metal, glass or calcareous items on display in museums or historical houses. The salts were dissolved in water and the aqueous solutions were examined by ion chromatographic analyses. At each site the concentration of acid vapours in the environment surrounding the objects were measured using passive samplers. Sets of laboratory tests were then conducted in an attempt to promote the formation of formate-based efflorescence products on the surface of limestone and egg shell as there is little evidence that formate salts are associated with calcareous objects.

\subsection{Experimental}

\subsection{Emission of acids from wooden blocks}

Six blocks of freshly cut wood $\left(2.5 \mathrm{~cm}^{3}\right)$ were placed at the bottom of $640 \mathrm{~cm}^{3}$ desiccators. The exact age of the trees used to supply the wood was not known but in all cases mature trees were sampled. Passive samplers were used to measure the concentration of acetic and formic acid vapours in each desiccator. Empty desiccators were monitored as sampling blanks. To assess the length of time taken to reach equilibrium, the desiccator holding samples of teak was measured on days $7,14,34$ and 41 . The results indicated that equilibrium had been established by day 7 and so the vapour phase concentrations of acids, in equilibrium with other wood samples, were measured 7 days after each experiment commenced.

\subsection{Passive Sampling}

Commercially available, (Gradko Ltd., U.K.), Palmes tubes were used to monitor atmospheres for acetic and formic acid vapours. The tubes had diffusional pathways of $7.1 \mathrm{~cm}$ with a cross-sectional area of $0.95 \mathrm{~cm}^{2}$. Samplers were prepared by placing 2 stainless steel mesh discs (Gradko, UK) inside a coloured polyethylene cap and pipetting on to the disc $40 \mu \mathrm{l}$ of a solution containing $1 \mathrm{M}$ potassium hydroxide and $10 \%(\mathrm{v} / \mathrm{v})$ ethylene glycol dimethyl ether. After drying for 1 hour, the cap with support was placed on one end of the polymethylmethacrylate diffusion tube and a colourless cap was used to seal the opposite end. Normally, samplers were prepared the same day as sampling commenced, otherwise they were stored at $4{ }^{\circ} \mathrm{C}$ until used. Sampling was initiated and terminated by removing and replacing the colourless cap, respectively. After sampling the stainless steel mesh discs, with trapped analytes, were removed from the tube and added to $5 \mathrm{~mL}$ of distilled water. The concentration of acetate and formate ions present in the washings were determined by ion chromatography as described previously [34,35]. The acetate and formate masses were converted to acetic acid and formic acid, respectively, and the concentration $\left(\mathrm{C}, \mu \mathrm{g} \mathrm{m}^{-3}\right)$ of acids in the vapour phase were calculated using the equation given below, where $\mathrm{M}$ is the mass $(\mu \mathrm{g}), \mathrm{L}$ is the diffusion length $(0.071 \mathrm{~m}), \mathrm{D}$ is the diffusion rate of acetic acid or formic acid in air $\left(1.1 \times 10^{-5}\right.$ or $1.27 \times 10^{-5} \mathrm{~m}^{2} \mathrm{~s}^{-1}$, respectively), A is the cross-sectional area of the tube $(9.5$ $\mathrm{x} 10^{-5} \mathrm{~m}^{2}$ ) and $\mathrm{t}$ is the time of exposure (s). 


$$
C=\frac{M L}{D A t}
$$

\subsection{Ion chromatography}

A Dionex DX100 ion chromatograph was used to analyse solutions of dissolved efflorescence and aqueous washings from swabs and passive samplers. The instrument comprised a degas module, single piston pump, pulse dampener and a conductivity cell. Chemical suppression was achieved using a selfregenerating suppressor, and the conductivity detector was set to $30 \mu \mathrm{S}$. For the determination of acetate and formate ions an AS4A analytical column, and AG4A guard column, (Dionex, U.K.) were used with a 6 $\mathrm{mM}$ eluent solution of disodium tetraborate decahydrate (BDH, Poole, U.K.) at $2 \mathrm{~mL} \mathrm{~min}^{-1}$. Other anions (chloride, nitrate, sulfate) were measured using an AS5 and AG5 set of columns (Dionex U.K.) with a 2.8 $\mathrm{mM}$ sodium carbonate $-2.2 \mathrm{mM}$ sodium bicarbonate eluent at $2 \mathrm{~mL} \mathrm{~min}^{-1}$. Cations were analysed using

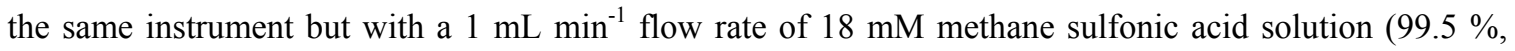
Aldrich) and CS12 main analytical and guard columns (Dionex U.K.). Quantification of analytes in sample solutions was achieved by dilution of $1000 \mu \mathrm{g} \mathrm{mL}^{-1}$ stock solutions (all salts were at least $99 \%$ pure as supplied from BDH, or Fisons, U.K.), to produce daily calibrant solutions in the range $1-10 \mu \mathrm{gL}^{-1}$. Linear regression analysis was performed to achieve calibration graphs for each analyte under study (acetate, formate, chloride, nitrate, sulfate, potassium, sodium, magnesium and calcium).

\subsection{Determination of salt stoichiometry}

Samples of efflorescent salts were analysed using ion chromatography after a known weight of the salt (approximately $5 \mathrm{mg}$ ) was dissolved in $10 \mathrm{~mL}$ of distilled water. Prior to injection into the chromatograph all solutions were filtered using an inorganic membrane filter (Anotop IC, $0.2 \mathrm{~mm}$ pore size, Whatman). The molar masses of anions and cations were determined and converted to stoichiometric ratios $\left(\mathrm{n}_{\mathrm{i}}\right)$ using the following equation where $m_{i}$ is the molar mass, $z_{i}$ is the charge of each ion, $E_{T}$ is the total theoretical number of anion (or cation) equivalences and $\mathrm{E}_{\mathrm{Exp}}$ represents the total experimental number of anion (or cation) equivalences in the solution; where an ion equivalence is taken as the product of its charge and molar mass $\left(\mathrm{m}_{\mathrm{i}} \mathrm{Z}_{\mathrm{i}}\right)$. Full details of the stiochiometric calculations have been published previously [16]. $n_{i}=\left[\frac{\left(m_{i} z_{i}\right)\left(E_{T}\right)}{E_{E x p}}\right]$

\subsection{Samples exposed to formic acid vapour}

In an attempt to mimic conditions within museum environments formic acid atmospheres were prepared at an approximate relative humidity (RH) of $54 \%$ using saturated magnesium nitrate salt solutions. A fixed volume of formic acid $(50,250$ or $1000 \mu \mathrm{L})$ was added to $50 \mathrm{~mL}$ of saturated magnesium nitrate and the solutions were placed at the bottom of desiccators to create atmospheres of 
approximately 10,30 or $100 \mathrm{mg} \mathrm{m}^{-3}$, respectively. The desiccators were sealed and after $24 \mathrm{~h}$ the atmospheric concentrations were measured experimentally using passive samplers. A range of materials intending to mimic mixed collections found in museums were added to the desiccators and monitored for up to 8 weeks. The materials included a limestone block $\left(8 \times 5 \times 1 \mathrm{~cm}^{3}\right)$, shell (half a chicken egg shell), copper, lead and brass coupons $\left(3 \mathrm{~cm}^{2}\right)$. Objects were also grouped by type (calcareous or metal) and exposed to similar concentrations of formic acid vapour.

Prior to pollutant gas exposure limestone blocks and egg shell samples were repeatedly washed in distilled water to remove any soluble salts from their pores; the absence of cations and anions was confirmed by ion chromatographic analysis of the washings, and metal coupons were cleaned using a polishing wheel. Two samples of each type of material were placed in the three formic acid environments. One sample was removed and weighed at at weekly intervals after being equilibrated in an oven at $30^{\circ} \mathrm{C}$ for $2 \mathrm{~h}$. The second sample was swabbed to measure the concentration of formate ions present on the surface of the object. An area of approximately $1 \mathrm{~cm}^{2}$ was swabbed repeatedly with a cotton wool swab wetted in distilled water. The area was swabbed 10 times in one direction then 10 times in a direction perpendicular to the first. The swab was then placed in a Sterlin container and $3 \mathrm{~mL}$ of distilled water was added to cover the end of the tip. The containers were sonicated for 3 min and the aqueous extracts were analysed by ion chromatography. Sampling blank experiments were also conducted by exposing samples to desiccators containing only $50 \mathrm{~mL}$ of a saturated solution of magnesium nitrate.

\subsection{Results and Discussion}

\subsection{Quantification of acetic and formic acid vapours emitted from freshly cut wood from mature trees.}

A total of 14 different wood types were examined for acetic and formic acid emission at room temperature $\left(18-21^{\circ} \mathrm{C}\right) 7$ days after they were placed in a sealed environment at $54 \% \mathrm{RH}$ (Table 1$)$. It was observed that acetic acid was given off at higher concentration than formic acid for every wood type except Yew, which emitted the lowest concentration of acetic acid vapour. As expected the amount of acetic acid released was higher for hardwood species compared to softwood species, although interestingly larch and red pine (both softwood species) emitted significant quantities of acetic acid. Several wood species such as afromosia, oak, obechie, beech, mahogany, larch or red pine were identified as the worst potential polluters of acetic acid vapour and caution would be advised if such materials were to be used in museum construction. This simple experiment demonstrates the need to carefully select wooden materials used to construct museum furniture and not to simply choose a softwood species assuming that its acetic acid emission will be reduced (compared to hardwood species). Recognising that the main source of acetic acid is from the hydrolysis of acetyl groups in the wood's hemicellulose the experiment was repeated with extreme humidity levels to examine both ends of the humidity spectrum. To create environments that were wet or dry (approx. 100 or $5.8 \% \mathrm{RH}$ ) beakers containing $30 \mathrm{~mL}$ of either distilled water or $70 \%$ sulfuric acid were placed in the sampling environments, respectively. At high relative humidity the concentration 
of acetic acid did increase significantly for afromosia, obechie, beech, ash, teak and birch (Table 2). However, levels were relatively constant for mahogany, cherry, oregon pine, white pine and yew which therefore may be good materials of choice if museum furniture is to be exposed to high humidity conditions. At the extreme low end of RH, very little acetic acid was released by any wood indicating that retardation of acetyl hydrolysis was achieved. It is recognized that it would not be practical for museums to use such extreme RH conditions, however this experiment does indicate that lower humidity values would be preferable, within accepted guidelines, and further experiments should be conducted to determine the affect of acid emission when decreasing relative humidity values between 30 and $60 \%$ RH. A few woods (oak, mahogany, cherry and red pine) were chosen to experience high temperatures $\left(45^{\circ} \mathrm{C}\right.$ ) and acetic acid concentrations drastically increased indicating that lower storage or display temperatures are recommended (Table 3). Indeed from this experiment it would appear that moderate control of temperature is more important than the relative humidity. It should also be noted that a wide range of other volatile organic compounds will be emitted from woods during the assessment period. However no other compounds were measured during this study as the intention was to focus on acetic and formic acid vapours and their association with acetate- and formate- based corrosion products.

To assess whether emission is related to the porosity of the wood, the bulk density $\left(\mathrm{g} \mathrm{cm}^{-3}\right)$ of each wood specimen was estimated by taking the average weight of a block of wood and dividing by its average volume. $\mathrm{pH}$ values of aqueous wooden extracts were also obtained by measuring the water extract from $1 \mathrm{~g}$ of wood shavings in $20 \mathrm{~mL}$ of distilled water. The results are given in Table 4 . The density and $\mathrm{pH}$ values were plotted against acetic acid concentration emitted at room temperature however no correlations were observed and plots demonstrated random scatter only. Thus it would appear that the rate of emission of acetic acid vapours studied here did not correlate with the density of the sample or its $\mathrm{pH}$ extract value.

\subsection{Three individual case studies: Analysis of corrosion products on objects held in contaminated environments}

Glass jewellery held in a display cabinet held in a former stately home in England exhibited signs of white efflorescence, which was focused on the metal fixings in the jewellery. It was suspected that the corrosion appeared as a result of pollution induced deterioration and that a wooden backboard was responsible for emitting organic acids into the cabinet. Passive sampling was conducted by placing three samplers inside the case, and a further three samplers were placed inside the gallery to act as sampling blanks. The mean acetic and formic acid vapour concentrations measured inside the case were $1130 \pm 44$ and $453 \pm 22 \mu \mathrm{g} \mathrm{m}^{-3}$, whereas the gallery contained $217 \pm 36$ and $54 \pm 23 \mu \mathrm{g} \mathrm{m}^{-3}$, respectively, confirming that there was an internally-generated source of acid vapours inside the case. A sample of salt was removed from the surface of the metal and added to $5 \mathrm{~mL}$ of distilled water. The salt was analysed for anions and cations using ion chromatography and formate was observed to be the predominant anion measured, at significantly higher concentrations than the other minor ions detected (chloride and nitrate). The efflorescence was also examined by XRF and lead was measured at high concentration indicating that 
the product was, principally, lead formate. Despite the high acetic acid concentration measured inside the cabinet acetate did not feature in the salt's stoichiometry and no lead acetate was measured in solution. This observation supports previous theories that lead acetate is unstable and, in the presence of carbon dioxide, will react to produce a water insoluble basic lead carbonate salt [21-24].

In the second case study historic glass objects dating back to the $19^{\text {th }}$ century were displayed in a wooden cabinet in a National museum in Scotland. A number of objects were displaying signs of efflorescence and samples were carefully removed from 110 glass artifacts. One of the cases used to store many of the objects was sampled using passive samplers and the concentrations measured were $2019 \pm 876$ and $433 \pm 192 \mu \mathrm{g} \mathrm{m}^{-3}$ for acetic acid and formic acids, respectively. These values were higher than those measured in the gallery at $246 \pm 4$ and $73 \pm 14 \mu \mathrm{g} \mathrm{m}^{-3}$. Salts were carefully removed from all 110 objects, dissolved in $5 \mathrm{~mL}$ of distilled water and the solutions were analysed by ion chromatography. Sodium was the major cation measured in every solution and was present in varying quantities up to $2030 \mu \mathrm{g} \mathrm{g}^{-1}$. Also present, although at significantly lower concentrations, were calcium, potassium or magnesium ions (with maximum measured concentrations of 25,10 or $6 \mu \mathrm{g} \mathrm{g}^{-1}$, respectively). The main anion component in the aqueous fraction of each salt was formate, which varied in quantities up to $3698 \mu \mathrm{g} \mathrm{g}^{-1}$. Minor anions measured in solutions included chloride, nitrate and sulfate ions, which were generally measured at concentrations below 154, 10 or $20 \mu \mathrm{g} \mathrm{g}^{-1}$, respectively. Acetate was not measured in most of the salt solutions and when it was detected it was measured at concentrations generally below $3 \mu \mathrm{g} \mathrm{g}^{-1}$. This case study supports the theory that sodium formate is detected as the principal corrosion product associated with glass in acid polluted environments; with formate being introduced via formic acid vapour inside the case and sodium ions being introduced from the glass matrix itself. With such high concentrations of acetic acid measured inside the case, it was likely that sodium acetate would also have been formed however with the case environment monitored at $57 \% \mathrm{RH}$, it is unlikely that sodium acetate would precipitate and thus it would remain in solution in the pores of the glass.

In the final case study, a number of ceramic tiles on display in a museum in Belgium, exhibiting signs of efflorescence growth, were examined. Passive samplers were supplied to monitor the conditions inside the display case and acetic acid vapour was measured at $1250 \pm 71 \mu \mathrm{g} \mathrm{m}^{-3}$, with formic acid vapour at $325 \pm 35 \mu \mathrm{g} \mathrm{m}^{-3}$. Samples of efflorescence were carefully removed from five of the affected ceramic tiles and salt samples $(5 \mathrm{mg})$ were dissolved in $5 \mathrm{~mL}$ distilled water and analysed using ion chromatography. The analysis confirmed that all of the salts contained acetate, chloride and nitrate as major anions in the salt, with calcium, and in one case sodium, being the major cations (Table 5). It is likely that the calcium and acetate ions will almost certainly have been present as a result of reaction between the calcium carbonate matrix and acetic acid vapours in the display cabinet environment, whereas sodium, nitrate and chloride ions will have been introduced to the tiles previously, possibly by ingress of salt-laden groundwater. 
The stoichiometry of the salts were determined (and normalised to calcium); two of the salts (samples 3 and 4 in Table 5) were identified as thecotrichite, sample 1 appeared to be a mixture of calclacite and sodium chloride, sample 2 was predominantly calcium acetate nitrate whereas sample 5 contained a mixture of calcium nitrate and calcium chloride. To ensure that the major ions were identified in each salt the total anion and cation equivalences were compared (i.e., $\Sigma\left(\mathrm{m}_{\mathrm{i}} \mathrm{z}_{\mathrm{i}}\right)$ for anions should equal $\Sigma\left(\mathrm{m}_{\mathrm{i}} \mathrm{z}_{\mathrm{i}}\right)$ for cations, where $\mathrm{m}_{\mathrm{i}}$ is the molar mass of the ion and $\mathrm{z}_{\mathrm{i}}$ is its charge). This was the case for salts 2 - 5 listed in Table 5. However there is an imbalance in the stoichiometry of salt 1 with a total anion equivalence of 3.04, compared to a cation equivalence of 1.82. Measured concentrations of ammonium, potassium or magnesium ions were so low that they were not thought to contribute to the stiochiometric composition. Either there was another cation present in the salt that had not been identified by ion chromatographic analysis or an experimental error had been introduced into the analysis giving lower calcium and/or sodium results. Unfortunately the sample of salt was depleted in the original analysis and the source of the ion imbalance was not confirmed. In general however, the salts observed on the surface of the tiles appeared to be dependant upon the concentration of ions present in the pores of the tiles. It was observed that despite the reasonably high concentration of formic acid in the storage environment, formate salts were not evident in any of the efflorescence products.

\subsection{Simulated experiments used to expose materials to formic acid vapour: mixed collections}

Three formic acid vapour concentrations were generated at approximately $54 \% \mathrm{RH}$ by adding different aliquots of formic acid (Sigma Aldrich, $>96 \%$ ) to saturated solutions of magnesium nitrate (Sigma Aldrich, $>98 \%$ ). The vapours generated were measured over a $17 \mathrm{~h}$ period on days 1 and 14 and the results indicated that the desiccators provided relatively stable environments, with formic acid concentrations of approximately 10,30 or $100 \mathrm{mg} \mathrm{m}^{-3}$ (Table 6). Two samples of each material type (limestone, shell and metal coupons) were placed in each of the three desiccators and the environments were re-sampled one week later (day 21 of the experiment); a significant drop in formic acid concentration was observed (see Table 6) indicating that formic acid had been adsorbed by the materials inside the desiccator. Despite the significant reduction in formic acid concentration, especially for the high formic acid environment, there was no obvious corrosion/efflorescence on the surface of the samples, and measured weight gains were all found to be negligible. The experiment was repeated and similar drops in formic acid concentrations were observed in all desiccators.

To expose the materials to high concentrations of formic acid vapour for 8 weeks, desiccator solutions were replenished weekly. The materials inside the contaminated environments continued to be a sink for the formic acid vapour for up to 8 weeks (Table 7). Desiccators containing acidic magnesium nitrate solutions were also monitored regularly to determine atmospheric concentrations in the absence of objects; no significant decreases in formic acid concentrations were measured over the same time period indicating that loss of formic acid was due entirely to sorption by materials inside the closed environment. One set of each material was weighed weekly, however no appreciable increase in weight was observed for 
the three metal coupons even after 8 weeks. The surface of the egg shell and limestone were swabbed and a small formate weight gain was recorded after the full period of exposure, but then only by 1.9 and $0.6 \mathrm{ng}$ $\mathrm{cm}^{-2} \mathrm{~d}^{-1}$, respectively, when exposed to the highest concentration of formic acid vapour. By the end of the 8 week exposure period formate ions were detected on the surface of all items, with highest concentrations being measured by the limestone sample (Table 8 ).

The objects were all examined visually and by scanning electron microscopy to assess whether corrosion had formed on the surface of the materials. Although the brass and copper coupons had dulled over the period of exposure no alteration to the surfaces were observed, whereas the lead coupon had become slightly pitted. Although measurement of the surface $\mathrm{pH}$ of the materials after exposure to formic acid would have been desirable, this was not performed as the surfaces were not sufficiently wet for conventional $\mathrm{pH}$ measurement and micro $\mathrm{pH}$ meters were not available.

\subsection{Simulated experiments used to expose materials to formic acid vapour: single objects}

It was recognized that by placing the materials into the same environment that the formic acid may have been preferentially adsorbed by the porous limestone. To examine this theory the metal coupons, eggshell and limestone materials were placed into individual desiccators each having an approximate formic acid concentration of $100 \mathrm{mg} \mathrm{m}^{-3}$. Passive sampling was initiated 8 hours after the materials were placed inside the desiccators and continued during the night. In the morning the formic acid solutions were replenished and sampling recommenced immediately thereafter for 8 hours. At the end of the day a fresh set of passive samplers were placed inside the desiccators and sampling continued during the night. This process was repeated over 4 days and the measured concentrations are given in Table 9. The formic acid vapour concentration inside desiccators with either metal coupons or egg shell remained relatively constant indicating that these materials were not particularly active at scavenging the formic acid vapour from air in the relatively short timescale. However, the vapour phase concentration of formic acid in the environment containing the limestone block did not exceed $78 \mathrm{mg} \mathrm{m}^{-3}$ for the daily readings and by night (approximately 15 hours after the acid solution was added to the environment containing the limestone block) the concentration had reduced further to approximately $40 \mathrm{mg} \mathrm{m}^{-3}$.

After a week of exposure to $100 \mathrm{mg} \mathrm{m}^{-3}$ the items were swabbed to determine the mass of formate on the surface of the items. The lead coupon had adsorbed formate at a rate of $2.3 \mathrm{ng} \mathrm{cm}^{-2} \mathrm{~d}^{-1}$ and it was very severely pitted. The copper and brass coupons adsorbed formate at rates of 18.6 and $22.9 \mathrm{ng} \mathrm{cm}^{-2} \mathrm{~d}^{-1}$, respectively and were very dull and discoloured with evidence of a green coloured coating on the surface of the coupons. The egg shell adsorbed formate at a rate of $107 \mathrm{ng} \mathrm{cm}^{-2} \mathrm{~d}^{-1}$ and yellowing was observed on the surface of the shell. Such visual signs of corrosion were not observed in the previous experiment as it would appear that the limestone block was preferentially scavenging formic acid from the air. In the individual desiccator experiment the surface of the limestone block was swabbed and it the mass of formate adsorbed was $35.7 \mathrm{ng} \mathrm{cm}^{-2} \mathrm{~d}^{-1}$. Based on the significant reduction of formic acid vapour in the presence of limestone it was thought that most of the formic acid was adsorbed into the pores of the limestone, and thus 
the total mass adsorbed was not reflected in the surface swab. During the course of this work no solid corrosion products were observed on any item and salt contamination remained in solution, therefore it was not possible to weigh corrosion products as was originally intended.

\subsection{Conclusions}

Acetic and formic acid vapours emitted from different wood species were measured using passive samplers and, in general, hardwood species emitted higher concentrations of acetic acid vapour than softwood species (although red pine and yew were exceptions to this rule giving off significant quantities of acetic acid vapour). The emission of acetic acid vapours from all hardwood species increased by a factor of 2 - 3 when the humidity of the environment was raised from $54 \%$ to $100 \%$. Softwoods were lesser affected by increased humidity. Control of temperature appears to be an important factor when controlling acid emission, at least for the samples of oak, mahogany, cherry and red pine studied here. Acetic acid concentrations increased by factors of $7-11$ when the storage temperature of the wood increased from $20^{\circ}$ $\mathrm{C}$ to $45^{\circ} \mathrm{C}$.

The formation of acetate- and formate- based corrosion products were observed on items held in heritage environments contaminated with acetic and formic acid vapour. Lead formate and sodium formate were identified as the principal corrosion products on leaded-jewellery or glass objects held in environments with 453 or $433 \mu \mathrm{g} \mathrm{m}^{-3}$ formic acid vapour, respectively. Acetate-based efflorescence products (thecotrichite, calclacite, calcium acetate nitrate) dominated salt product formation on ceramic tiles held in environments contaminated with acetic acid vapour $\left(1250 \mu \mathrm{g} \mathrm{m}^{-3}\right)$. In simulated environments where items were exposed to elevated levels of formic acid vapour (approximately $100 \mathrm{mg} \mathrm{m}^{-3}$ ) limestone was shown to preferentially scavenge formic acid from the air when in the presence of egg shell and metal coupons.

\section{$\underline{\text { Acknowledgments }}$}

Jane Ballany and Neil Patterson are acknowledged for assistance with the wood, case study and formic acid vapour results, respectively. Lieve Halsberghe, Barry Knight, Kathy Eremin and Norman Tennent are all acknowledged for collection of efflorescence samples and assistance with passive samplers on site. 


\section{References}

1. Arni, P.C., Cochrane, G.C. and Gray, J.D., The emission of corrosive vapours by wood, I. Survey of the acid-release properties of certain freshly felled hardwoods and softwoods. Journal of Applied Chemistry, 1965. 15: p. 305 - 313.

2. Arni, P.C., Cochrane, G.C. and Gray, J.D., The emission of corrosive vapours by wood, II. The analysis of vapours emitted by certain freshly felled hardwoods and softwoods by gas chromatography and spectrophotometry. Journal of Applied Chemistry, 1965. 15: p. 463 - 468.

3. Farmer, R.H., Corrosion of metals in association with wood. Part I Corrosion by acidic vapours from wood. Wood, 1962. 27: p. 326 - 328.

4. $\quad$ Farmer, R.H., Corrosion of metals in association with wood: part 2. Corrosion of metals in contact with wood. Wood, 1962(November): p. 443 - 446.

5. Budd, M.K., Corrosion of metals in association with wood. Applied Materials Research, 1965(April): p. 124 - 125.

6. $\quad$ Farmer, R.H., Chemistry in the Utilization of Wood, Pergamon Press, Oxford, 1967.

7. Scarisbrick, R., Modern Methods of Plant Analysis, Springer-Verlag, Berlin, 1955, 447.

8. Blackshaw, S.M. and Daniels, V.D., Selecting safe materials for use in storage and display in museums, in 5th triennial meeting of ICOM committee for conservation. 1978, ICOM committee for conservation: Zagreb. p. 78/23/2.

9. Oddy, W.A., Coins and Medals, ed. Simpson, M.T. and Huntley, M., 1992, London: Conran Octopus Ltd.

10. Tennent, N.H.and .Baird, T., Deterioration of mollusca collections: identification of shell efflorescence. Studies in Conservation, 30 (1985) 73 - 85.

11. Van Tassel, R., On the crystallography of calclacite, $\mathrm{Ca}(\mathrm{CH} 3 \mathrm{COO}) \mathrm{Cl}$. 5H2O. Acta Crystallographica, 11 (1958) 745 - 746.

12. Fitzhugh, E.W.and. Gettens, R.J., 'Calclacite and other efflorescent salts on objects stored on wooden objects' in Science and Archaeology. 1971, Cambridge, MA: MIT Press.

13. Paterakis, A.B. A preliminary study of salt efflorscence in the collection of ancient Agora, Athens, Greece. in 9th Triennial meeting, ICOM Committee for Conservation. 1990. Dresden, Germany: ICOM, Committee for Conservation.

14. Brokerhof, A.W., M, Deterioration of calcareous materials by acetic acid vapour, in 11th triennial meeting ICOM committee for conservation. 1996, James and James (Science Publishers): Edinburgh, Scotland. p. 769- 775.

15. Linnow, K., Halsberghe, L. and Steiger, M., Analysis of calcium acetate efflorescences formed on ceramic tiles in a museum environment. Journal of Cultural Heritage, 8 (2007) 44 - 52.

16. Gibson. L.T., Cooksey, B.G., Littlejohn, D. and Tennent, N. H., Characterisation of an unusual crystalline efflorescence on an Egyptian limestone relief. Analytica Chimica Acta, 337 (1997) 151 - 164.

17. Gibson. L.T., Cooksey, B.G., Littlejohn, D. and Tennent, N. H., Investigation of the composition of a unique efflorescence on calcareous museum artifacts. Analytica Chimica Acta, 337 (1997) 253 - 264.

18. Nockert, M.a.W., T., Storage of archaeological textile finds in sealed boxes. Studies in Conservation, 23 (1978) 38 - 41.

19. Robinet, L., Eremin, K., Cobo del Arco, B. and Gibson, L. T., A Raman spectroscopic study of pollution-induced glass deterioration. Journal of Raman Spectroscopy, 35 (2004) 662 - 670.

20. Padfield, T., Erhardt, D., and Hopwood, W. Trouble in Store: Science and Technology in the service of conservation. in 9th International IIC Congress. 1982. Washington DC: IIC.

21. Plenderleith, H.J. and Werner, A.E.A, The Conservation of Antiquities and Works of Art. 2nd ed. 1971, London: Oxford University Press.

22. Edwards, R., Bordass, W. and Farrell, D., Determination of acetic and formic acid in lead corrosion products by ion exchange chromatography. Analyst, 122 (1997) 1517 - 1520.

23. Tennent, N.H., Tate, J. and Cannon, L., The corrosion of lead artefacts in wooden storage cabinets. Scottish Society for Conservation and Restoration Journal, 4 (1993) 8 - 11.

24. Lane, H., The conservation and storage of lead coins in the department of coins and medals, British Museum, in Recent advances in conservation and analysis of artefacts. 1987: London. p. 149 - 153. 
25. Tetrault, J., Sirois, J. and Stamatopoulou, E., Studies of lead corrosion in acetic acid environments. Studies in Conservation, 43 (1998) 17 - 32.

26. Allen, G.C.and Black, L., Role of organic acids in lead patination. British Corrosion Journal, 35 (2000). 39 - 42.

27. Weierter, V.and Tate, J., The corrosion of 'lead' communion tokens. in Conservation Science in the U.K. 1993. Glasgow: James and James (Science Publishers).

28. Tennent, N.H. and Baird, T., The identification of acetate efflorescence on bronze antiquities stored in wooden cabinets. The Conservator, 16 (1992) 39 - 47.

29. Thickett, D., Bradley, S. and Lee, L., Assessment of the risk of metal artifacts posed by volatile carbonyl pollutants, in Metal 98. 1998, James and James (Science publishers Ltd.). p. 260 - 264.

30. Tennent, N.H., Cooksey, B. G., Littlejohn, D., Ottaway, B. J., Tarling, S.E. and Vickers, M., Unusual corrosion and efflorescence products on bronze and iron antiquities stored in wooden cabinets, in Conservation Science in the U.K. 1993, James and James (Science Publishers): Glasgow. p. 60 - 66.

31. Lopez-Delgado, A., Cano, E., Bastidas, J.M. and Lopez, F.A., A laboratory study of the effect of acetic acid vapour on atmospheric copper corrosion. Journal of electrochemical society, 145 (1998) 4140 - 4147.

32. Gibson, L.T., Cooksey, B. G., Littlejohn D., Tennent, N. H., Linnow K. and Steiger M., The mode of formation of thecotrichite, a widespread calcium acetate chloride nitrate efflorescence. Studies in Conservation, 50 (2005) 1 - 10.

33. Cobo del Arco, B., In The conservation of glass and ceramics: research, practice and training, Tennent, N. H., (ed.), James and James, London, 1999, 29.

34. Gibson, L.T., B.G. Cooksey, D. Littlejohn and N.H. Tennent, Determination of experimental diffusion coefficients of acetic acid and formic acid vapours in air using a passive sampler, Analytica Chimica Acta, 341 (1997) 1 - 10.

35. Gibson, L.T., B.G. Cooksey, D. Littlejohn and N.H. Tennent, A diffusion tube sampler for the determination of acetic acid and formic acid vapours in ambient air, Analytica Chimica Acta, $\mathbf{3 4 1}$ (1997) 11 - 19. 